\title{
ALFABETISMO CIENTÍFICO: NOVOS DESAFIOS NO CONTEXTO DA GLOBALIZAÇÃO
}

\author{
Sibele Cazelli (Museu de Astronomia e Ciências Afins, MAST/MCT) \\ Creso Franco (Departamento de Educação, PUC-RJ
}

O presente trabalho tem como objetivo esboçar uma visão geral das questões históricas e conceituais que cercam o conceito de globalização, tal qual aparece nos trabalhos dos sociólogos Anthony Guiddens, David Held, Anthony McGrew e Nicolau Sevcenko, bem como delinear suas implicações sobre os padrões de relação da sociedade com a ciência. A partir dessas reflexões sobre modernidade, globalização e relação entre ciência e sociedade, examinamos o tema dos níveis de cultura e de alfabetismo científico demandados para a inserção na sociedade contemporânea. As análises evidenciaram que em domínios crescentes da vida social, cidadãos serão chamados a intervir em decisões sobre as quais os especialistas não têm a "resposta certa".

Palavras-Chave: alfabetismo científico; ciência e globalização; risco e educação em ciências

\section{Introdução}

Para lidar com a transição do século XX para o século XXI e com a contínua e acelerada mudança tecnológica que provoca efeitos expressivos em inúmeros campos da experiência humana, Nicolau Sevcenko (2001) usa a imagem de uma viagem de montanha-russa para indicar algumas das tendências mais marcantes desse período. Na primeira fase da viagem, 0 ritmo de subida é tranquilo, seguro e agradável. De repente, a segunda fase: uma queda vertiginosa, com tal velocidade que as referências do espaço circundante são perdidas. Ocorre, então, uma interrupção repentina da descida e o início de uma nova subida, diferente da primeira, tanto em relação ao ritmo, quanto ao tempo. Uma espécie de preparação para a fase subseqüente - a terceira - um mergulho rápido e oscilante para a direita e a esquerda, como uma entrada nas curvas espiraladas de um parafuso, culminando com o loop - uma volta completa em forma de laço. Ao chegar ao fim dessa viagem, segundo o autor, assimila-se a lição da montanha-russa: "compreende-se o que significa estar exposto às forças naturais e históricas agenciadas pelas tecnologias modernas. Aprende-se os riscos implicados tanto em se arrogar o controle dessas forças, quanto em deixar-se levar de modo apatetado e conformista por elas" (Sevcenko, 2001:13).

Nosso intuito é o de tomar emprestada essa imagem de Sevcenko (2001) para esboçar uma visão geral das questões históricas e conceituais que cercam o conceito de globalização, tal qual aparece nos trabalhos dos sociólogos Anthony Guiddens (1991; 2000a; 2000b), David Held e Anthony McGrew (2001), e suas implicações sobre os padrões de relação da sociedade com a ciência. A partir dessas reflexões sobre modernidade, globalização e relação entre ciência e sociedade, examinamos o tema dos níveis de cultura e de alfabetismo científico demandados para a inserção na sociedade contemporânea. 


\section{Primeira fase da viagem de montanha-russa: a subida}

De acordo com Sevcenko (2001), essa fase da viagem de montanha-russa - a ascensão contínua, metódica e persistente - pode representar o longo período que se inicia no século XVI e que se estende até a primeira metade do século XIX. Já desde séculos anteriores, notadamente na época feudal, assistiu-se, no Ocidente, a criação de numerosas cidades nas quais desabrocharam um novo modo de vida e uma nova civilização urbana, devido ao fortalecimento do comércio e à emergência do mercador enquanto centro da vida econômica. Essas transformações propiciaram na sociedade ocidental, na confluência de dois universos nobres e camponeses -, o aparecimento de um novo homem, o burguês. Portador de uma perspectiva de mudança, esse novo homem introduziu a noção de que o mundo era moldável, o que modificou não apenas sua relação com a natureza mas também a relação entre os homens, principalmente no que diz respeito ao trabalho. Portanto, a burguesia foi um grupo social, com disposição emocional e moral capaz de instaurar uma nova relação com o mundo (Pernoud apud Nóvoa, 1991).

A cultura industrial ocidental, na Europa dos séculos XVII e XVIII, foi moldada pelo Iluminismo - mais que um movimento, um modo de pensar. Naquele contexto, a Revolução Científica do século XVII transformou a concepção que a maioria das pessoas com algum grau de instrução tinha a respeito do mundo que habitavam. Os filósofos do lluminismo pressupunham que a Natureza era regulada por um sistema de leis universais e que o homem era, em muitos aspectos, uma parte dessa Natureza. Desse modo, a compreensão que o homem tinha de si mesmo e da sociedade só podia ser alcançada pelos métodos científicos da observação. Para Giddens (2000a:13-14), os pensadores do lluminismo observaram uma norma simples, mas poderosa, isto é, "quanto mais formos capazes de compreender racionalmente o mundo, e a nós mesmos, mais poderemos moldar a história para os nossos próprios propósitos. Temos de nos libertar dos hábitos e preconceitos do passado a fim de controlar o futuro".

Em continuidade a essa perspectiva, surgiram na Europa ocidental e em seus territórios coloniais, nos séculos XVIII e XIX, os Estados modernos, afirmando uma correspondência entre a soberania, o território e a legitimidade. O aprimoramento do conceito de soberania "propriedade que tem um Estado de ser uma ordem suprema que não deve a sua validade a nenhuma outra ordem superior" (Ferreira, 1999:1868) -foi muito importante para legitimar o direito de governar um território delimitado, concretizando 0 desenvolvimento e 0 estabelecimento desses Estados modernos como Estados-nação, cujos traços definidores são: "a territorialidade que fixa fronteiras exatas, o controle monopolista da violência, a estrutura impessoal do poder político e a afirmação singular da legitimidade com base na representação e na responsabilidade" (Held e McGrew, 2001:26).

No início do século XIX, os grupos sociais dominantes da Europa entraram em uma fase de desenvolvimento tecnológico que Ihes assegurou o domínio de fontes de energia, de novos meios de transportes e comunicação, de armamentos e conhecimentos especializados. Essa situação garantiu a conquista de enormes dimensões do globo terrestre, de suas populações e recursos, impondo uma "hegemonia apoiada na idéia de uma vocação inata da civilização européia para o saber, o poder e a acumulação de riquezas" (Sevcenko, 2001:15). 
Giddens (1991:17) ao desenvolver uma análise institucional da modernidade com ênfases cultural e epistemológica afirma que a "modernidade refere-se a estilo, costume de vida ou organização social que emergiram na Europa a partir do século XVIII e que ulteriormente se tornaram mais ou menos mundiais em sua influência”. Segundo esse autor, os fundadores clássicos da sociologia - Marx, Durkheim e Weber - viam a era moderna como um período no qual as possibilidades abertas poderiam ter tanto características positivas quanto negativas. Marx, cujas idéias tiveram inspiração no pensamento lluminista, anteviu uma revolução como culminação do conflito entre os capitalistas e o proletariado, a ser seguida pela construção de uma sociedade sem classes, comunista. Concebia a luta de classes como conseqüência de contradições estruturais, ao mesmo tempo que vislumbrava a emergência de um sistema social mais humano, que iria gerar maior riqueza e distribuir essa riqueza de maneira mais equânime. Durkheim acreditava que a expansão do industrialismo, doutrina que considerava a indústria o fim principal da sociedade, estabeleceria uma vida social harmoniosa, integrada por meio de uma combinação da divisão do trabalho e do individualismo moral. Para Weber a ênfase estava na racionalização expressa na tecnologia e na organização das atividades humanas. Para além dessas evidentes diferenças entre esses autores - em especial Marx, de um lado, e Durkheim e Weber, de outro - encontra-se uma visão otimista acerca do progresso, da ciência e da tecnologia.

\section{Segunda fase da viagem de montanha-russa: a queda vertiginosa}

Esses três sociólogos viveram o suficiente para conhecer em parte a segunda fase da viagem de montanha-russa - aquela da queda vertiginosa, interpretada como um novo salto no processo de desenvolvimento tecnológico (segunda metade do século XIX à primeira metade do XX), caracterizado pela incorporação e aplicação de novas teorias científicas, propiciando o domínio e a exploração de novos potenciais energéticos (desenvolvimento das aplicações da eletricidade: usinas hidro e termelétricas); o uso dos derivados de petróleo (motores de combustão interna); o surgimento das indústrias químicas, das fundições, usinas siderúrgicas e dos primeiros materiais plásticos. No mesmo impulso foram desenvolvidos novos meios de transportes (carros, caminhões, trens expressos, transatlânticos, aviões etc.), além dos novos meios de comunicação: telégrafo com e sem fio, o rádio, o gramofone, a fotografia e o cinema (Sevcenko, 2001).

Esse período foi intensamente marcado por uma crença otimista na força unificadora do Progresso - todos os povos do globo terrestre seriam finalmente atraídos para a seara da Civilização. As bases teóricas dessa ideologia tiveram por fundamento a equação "Progresso = Civilização" (Neves, 2001).

É interessante destacar, nesse cenário, o papel desempenhado pelas chamadas Grandes Exposições Internacionais da Indústria ocorridas na segunda metade do século XIX das quais o Brasil participou desde 1862, ou seja, desde a terceira Exposição realizada em Londres. As Exposições Internacionais eram um fascinante monumento à capacidade técnica com que a sociedade industrial burguesa manifestava seu orgulho. Foram verdadeiros palcos para a representação de uma convicção no progresso, na ciência e na técnica. Era a equação "Progresso = Civilização", representando ou afirmando uma crença, como um ideal que propõe 
uma meta a ser alcançada. A cada Exposição (da segunda metade do século XIX à segunda década do século XX - de 1851 a 1922 - aconteceram 17 eventos) mostrava-se o caminhar das nações em direção ao acúmulo de aquisições materiais e de conhecimentos objetivos capazes de transformar a vida social e de conferir-lhe maior significação no contexto da experiência humana. Elas se caracterizaram como espaços onde as mercadorias, e sobretudo as máquinas, estavam expostas para serem vistas, contempladas como ícones dos novos tempos, da modernidade e do poder de criação da indústria (Neves, 2001).

De modo geral, os lugares geográficos dados a esses eventos "eram sempre portadores de símbolos que representariam a nação e o progresso" (Kuhlmann Júnior, 2001:11). A primeira Exposição Internacional da Indústria, inaugurada em Londres, em maio de 1851, ocupava o Palácio de Cristal (uma gigantesca construção arquitetônica com 563 metros de comprimento, 124 metros de largura e 33 metros de altura) que serviu ao mesmo tempo de espaço e símbolo dessa exposição. "Encarnava a vontade prático-funcionalista de uma época" (Plum apud Kuhlmann Júnior, 2001:26), anunciando uma nova forma de cooperação entre a ciência, a técnica e a indústria.

O aspecto relevante das Exposições Internacionais que aconteceram por todo o mundo ocidental e dos Congressos ocorridos em sua órbita foi a incorporação da temática educacional que, desde 1862, em Londres, se fez presente. A partir daí, a educação obteve cada vez mais destaque, ocupando espaços privilegiados nessas mostras, ao lado da exibição da produção industrial e artísticas e da demonstração de novidades tecnológicas (Kuhlmann Júnior, 2001).

De acordo com esse autor (Kuhlmann Júnior, 2001:9), as Exposições, além de transparecerem na sua organização uma

intenção didática, normatizadora, civilizadora, (...) elas prestigiaram a educação como um signo de modernidade, difundindo um conjunto de propostas nessa área, que abarcava materiais didáticos, métodos pedagógicos e diferentes instituições da creche ao ensino superior, passando pelo ensino profissional e pela educação especial.

Portanto, nesses eventos internacionais (e também nas Exposições Nacionais preparatórias), a educação era identificada como elemento constitutivo da sociedade moderna. A questão educacional aparecia não como algo pertencente apenas ao espaço da escola ou do sistema de ensino, mas como algo impulsionador e estruturador de toda a sociedade.

As dimensões educativas das Exposições e dos Congressos delineavam uma "pedagogia do progresso" com o intuito de efetuar uma educação normativa para os mais diversos aspectos da vida social. "Pretendia-se educar as elites dos países visitantes - bem como as elites nacionais. Ministrava-se uma pedagogia das nações, expressa nas lições de organização de um Estado moderno" (Kuhlmann Júnior, 2001:233). Havia um padrão que norteava o jeito de se pertencer ao mundo civilizado, consolidando as tendências de mistificação da ciência. A vinculação a esse conhecimento passou a ser a principal justificativa das propostas dos grupos participantes desses eventos, voltados para a educação. Em todos os lugares se encontrava os adjetivos "novo" e "científico". 
Na passagem para o século XX, o otimismo, a expansão das conquistas européias e a confiança no progresso pareciam ter atingido o seu ponto mais alto. No entanto, os três fundadores clássicos da sociologia (Marx, Durkheim e Weber) vislumbraram que as possibilidades abertas pela era moderna poderiam ter, tanto características positivas ("o lado da oportunidade", já apresentado nos parágrafos anteriores), quanto negativas ("o lado sombrio"). Entre as características negativas, viram que o trabalho industrial moderno tinha conseqüências degradantes, submetendo muitos indivíduos à disciplina de uma rotina maçante, repetitiva e que exigia pouco pensamento ou julgamento. Marx era especialmente crítico desse aspecto, o que o levou a desenvolver sua crítica à "divisão social do trabalho" estimulada pela propriedade privada dos meios de produção. Já Durkheim, embora registrasse problemas pontuais relativos aos processos de industrialização, tinha posicionamento bastante distinto de Marx e enfatizava as oportunidades abertas pela "divisão do trabalho social". Outro exemplo de preocupação com a qual Durkheim e Weber tiveram que lidar diz respeito ao desenvolvimento do poder militar. Afinal, esses sociólogos viveram para testemunhar a Primeira Guerra Mundial: destruição em massa de cidades e de seres humanos, potencializada e aumentada pelos novos recursos tecnológicos disponíveis (Giddens, 1991).

Ainda segundo Giddens (1991), embora Durkheim tenha morrido antes da conclusão desse conflito, a guerra destruiu sua previsão de que uma ordem industrial pacífica e integrada seria promovida pelo industrialismo. Mesmo Weber que deu mais atenção ao papel do poder militar, deslocou o foco de sua análise para a racionalização e a burocracia. As análises escritas pelos pensadores sociais, no início do século XX, não previram a "industrialização da guerra", ou seja, a conexão das inovações industriais com o poder militar. Mas durante e após a I Guerra Mundial prevaleceu a crença de que se tratava de uma guerra para acabar com todas as guerras, o que foi desmentido muito rapidamente pela eclosão da II Guerra Mundial.

\section{Terceira fase da viagem de montanha-russa: o clímax da descida acelerada - o loop}

Ao final da II Guerra Mundial, o ocidente contabilizava a existência, em um período de apenas 30 anos, de dois conflitos bélicos em escala mundial, da depressão econômica do final da década de 1920, da emergência do fascismo e do holocausto. Já não havia razões para encarar o progresso e a civilização como destino inexorável. Enquanto muitos àquela época viam na experiência soviética uma alternativa à sucessão de crises que o desenvolvimento capitalista tinha levado, outros enxergavam no Estado de bem-estar social propugnado pela social democracia a alternativa tanto às mazelas do capitalismo em descontrole quanto ao totalitarismo do socialismo do bloco soviético. A inspiração econômica do consenso do Estado de bem-estar social no pós-guerra era expressa pelo pensamento de John M. Keynes. Avaliando o pensamento de Keynes, Giddens (2000b:9), sublinhava que o economista inglês "não era um socialista; partilhava, contudo, de algumas idéias que Marx e o socialismo enfatizavam. (. . .) Encarava o capitalismo como dotado de qualidades irracionais, mas acreditava que seria possível controlá-las para salvar o capitalismo de si mesmo".

Em vários países da Europa, o capitalismo de mercado foi estabilizado pela criação de uma economia mista, caracterizada pela estatização de indústrias fundamentais para o interesse nacional que não deveriam ficar em mãos privadas. Uma preocupação dominante dos 
social-democratas foi a busca por uma maior igualdade, protegendo os indivíduos ao longo do ciclo da vida e fomentando o processo de evolução dos direitos de cidadania. A idéia de controle, via conhecimento, continuava tendo centralidade no novo contexto pós II Guerra Mundial e o próprio Estado de bem- estar social pode ser visto como um mecanismo de segurança, de administração dos riscos associados ao desemprego, à doença e à velhice.

Muito embora alguns autores interpretem a emergência do neoliberalismo como "reação teórica e política veementemente contra o Estado intervencionista e de bem- estar" (Anderson, 1996:9), outros autores enfatizam que o fortalecimento da perspectiva neoliberal na década de 1980 precisa ser compreendida como decorrente da incapacidade de o Estado de bem-estar social e da esquerda tradicional em dar conta de novos desafios, relacionados com a dificuldade de o conhecimento propiciar controle sobre o mundo físico e sobre a vida social. A esse respeito, Giddens (1997:219) enfatiza que vivemos atualmente em um mundo cujas características não podiam ser antecipadas, no século XIX e em boa parte do século XX, pelos pensadores ligados à tradição iluminista. Nas suas palavras:

esses pensadores acreditavam, com bastante propriedade, que quanto mais viéssemos a conhecer sobre o mundo, enquanto coletividade humana, mais poderíamos controlá-lo e direcioná-lo para nossos próprios propósitos. Aumentar o conhecimento produzido com respeito ao mundo social e natural conduziria a uma maior certeza sobre as condições sob as quais conduzimos nossas vidas [. . . no entanto,] as conexões entre o desenvolvimento do conhecimento humano e o autoentendimento humano provaram ser mais complexas do que sugere essa visão.

Esse autor ressalta que, freqüentemente, defrontamo-nos com situações cujo desenvolvimento só pode ser equacionado em termos de cenários que, por vezes, são divergentes ou mesmo antagônicos. Possibilidades e riscos apresentam-se de modo tal que não há como prever ou controlar deterministicamente o resultado de processos em curso. Por certo, a humanidade sempre conviveu com situações de imprevisibilidade, como pode ser exemplificado por muitas catástrofes climáticas e geológicas, outrora muito menos previsíveis e com implicações menos controláveis. A novidade da situação de risco na modernidade reside no fato de que "muitas incertezas com que nos defrontamos hoje foram criadas pelo próprio desenvolvimento do conhecimento humano" (Giddens, 1997:220). Trata-se, portanto, de "riscos fabricados", como exemplificados por aqueles associados a problemas ecológicos ou conflitos nucleares.

Outro aspecto enfatizado pelo autor em questão diz respeito ao papel desempenhado pela confiança dos agentes sociais nos "sistemas especialistas" (expert systems), como elemento fundamental das relações sociais modernas. Para ele, "sistemas especialistas" são "sistemas de excelência técnica ou competência profissional que organizam grandes áreas dos ambientes material e social em que vivemos hoje" (Giddens, 1991:35). Tem em mente a noção de que os indivíduos, ao relacionarem-se socialmente, baseiam-se na confiança em especialistas. Exemplos seriam a relação médico-paciente, a de pais e professores, engenheiros e operadores, a de passageiros com relação a tripulantes etc. A modernidade convivia, portanto, desde há muito, com a confiança em "sistemas especialistas", a despeito da recorrente fabricação de riscos. Tomamos consciência da transição da "sociedade de risco 
residual" para a "sociedade de risco global" pela emergência no cenário público das ameaças fabricadas e dos conflitos associados a essas ameaças (Beck, 1997:15). É, portanto, a "sociedade de risco global" ou, nos termos de Giddens (1991), a "modernidade radicalizada" que desnuda e aprofunda a tensão entre risco e confiança em "sistemas especialistas".

\section{Risco, Incerteza e Educação em Ciências}

A modernidade, no sentido atribuído por Giddens (1991) a esse termo, é um processo originado na Europa renascentista. No entanto, as instituições da modernidade tiveram um processo de constituição mais longo, estendendo-se, no caso europeu, até o final do século XIX. A escolarização generalizada é uma dessas instituições modernas que, no caso brasileiro, só surgiu no horizonte do século XX. Ao longo daquele século, diversos autores participaram do debate acerca do potencial de reprodução ou de autonomização possibilitado pela educação. Muito freqüentemente indaga-se sobre as razões e o sentido da manutenção de abordagens dogmáticas no ensino de ciências, a despeito da ineficácia dessas abordagens para 0 aprendizado significativo de ciências.

Diferentemente de autores que interpretam a permanência das abordagens ineficazes como decorrentes de mecanismos econômicos relacionados com a formação de exércitos de mão de obra de reserva (Frigotto, 1998), entendemos que a insistência em abordagens dogmáticas tem sua funcionalidade por meio da valoração da confiança em "sistemas especialistas", apesar de sua ineficácia em termos de ensino e de aprendizagem de ciência. Essas abordagens transmitem confiança em "sistemas especialistas", ainda que ao preço do recrudescimento do aspecto de reprodução, em detrimento das possibilidades de autonomização a partir da educação. Essa tendência precisava ser parcialmente relativizada, sem o que a própria formação de especialistas estaria ameaçada. Isso tem sido alcançado por dois processos complementares. O primeiro é aquele que tem garantido, em um dado nível de ensino, abordagens pedagógicas reflexivas para os filhos de determinadas parcelas da população. O segundo está associado à maior reflexividade proporcionada pelo ensino nos níveis mais elevados e nos ramos de especialização de maior status social.

Sendo o Estado moderno um espaço de contradições, a tendência hegemônica apresentada acima tem sido desafiada por alternativas que buscam aprofundar a democracia na sociedade a partir da oferta de oportunidades educacionais reflexivas para amplas parcelas da população estudantil. Para essa perspectiva, a emergência da "sociedade de risco global" introduz possibilidades auspiciosas. Essas possibilidades são melhor apreciadas quando uma especificação adicional no conceito de "sociedade de risco global" é introduzida, de modo a diferenciar riscos que, por mais severos que sejam, podem ter suas conseqüências determinadas previamente daqueles cujas conseqüências são marcadas pela incerteza. $O$ exemplo apresentado logo abaixo ajudará a clarificação desse ponto.

A ciência produz não só soluções para questões sociais mas também novos problemas, alguns dos quais - a exemplo das armas atômicas - oferecem riscos para a própria sobrevivência da humanidade. Nesse caso, o risco consiste na utilização de artefatos construídos a partir de processos e resultados científicos. Quanto às conseqüências associadas à efetiva utilização em massa desses artefatos, a ciência não produz incertezas. Pelo contrário, 
há previsões inequívocas acerca do destino da humanidade caso ocorra utilização em massa de armamentos nucleares. Em resumo, o risco existe e a produção da situação de risco está associada à ciência, mas o risco não está relacionado à incapacidade da ciência em produzir diagnósticos seguros acerca dos eventos potencialmente desastrosos.

Quando o tema em questão passa a ser a manipulação genética ou diversas outras mudanças produzidas pelo homem no meio ambiente, a situação apresenta-se significativamente diferente daquela examinada no caso das armas atômicas. A diferença consiste no fato de que, nesses novos casos, a ciência torna-se incapaz de produzir diagnósticos seguros. Há que se conviver com a probabilidade e com o não determinismo. Encontramo-nos, portanto, em uma situação em que características intrínsecas à ciência contemporânea passam a fazer parte da relação da ciência com os diversos agentes que tomam decisões em âmbito governamental, empresarial e comunitário. Em última instância, as referidas características da ciência precisarão ser consideradas pelos cidadãos que terão que se posicionar em diversas circunstâncias, incluindo a eleitoral.

A relação entre ciência e sociedade conduz, então, àquilo que Giddens (1991) denominou de "fabricação da incerteza". Nesse contexto, é crescente o número de circunstâncias em que se faz necessário "agir na urgência, decidir na incerteza". Essa expressão, cunhada por Perrenoud (1996) para enfatizar que o professor, em sala de aula, não tem como agir de modo plenamente alicerçado nas práticas científicas, torna-se, na sociedade de risco, uma imagem adequada para sintetizar processos decisórios em que cidadãos, políticos, gestores públicos ou empresários tomam decisões acerca de questões como a dos alimentos transgênicos e outros temas de grande impacto social. Nesses casos, como nos lembram Young e Glanfield (1998), freqüentemente não se resolve o problema com a consulta a comitês de cientistas pois esses, não raramente, produzem o dissenso.

A emergência da sociedade de risco renova e re-significa as exigências acerca da educação em ciências. Os novos desafios estão relacionados com as características centrais das sociedades de risco e com as demandas que esse tipo de sociedade coloca para os cidadãos. Referimo-nos à concomitante constância da ciência nos diversos aspectos da vida social, à inviabilidade da convivência com o risco, com a probabilidade e com a incerteza em temas de grande relevância social e à acelerada renovação e multiplicação de assuntos relacionados com ciência, demandando posicionamento e decisão. As "sociedades de risco global" minam, portanto, a própria confiança nos sistemas especialistas, o que limita a funcionalidade do ensino dogmático de ciências.

\section{A posição de cabeça para baixo do loop: globalização, o que é e quais as implicações para a educação?}

A rápida expansão da interdependência política e econômica, especialmente entre as nações ocidentais, gerou muita reflexão sobre a crescente inter-relação das questões humanas. Depois do colapso do socialismo/comunismo e da consolidação mundial do capitalismo, a idéia de globalização e a avaliação de suas conseqüências constitui um tema impossível de ser ignorado, seja no debate intelectual, seja no popular (Giddens, 2000a; Giddens, 2000b). 
Embora as referências à globalização tenham se tornado comuns nas duas últimas décadas (1980 e 1990), segundo Held e McGrew (2001), o conceito em si remonta a um período muito anterior. Sua origem está no trabalho de muitos intelectuais do século XIX e início do século $X X$, desde sociólogos até estudiosos de geopolítica, que reconheceram que a modernidade estava integrando o mundo.

Uma consulta ao Dicionário do Pensamento Social do Século XX revela que a palavra "global", nos anos de 1960, passou a ser usada para significar "pertencente ao mundo" ou "mundial", sendo que alguns estudiosos a consideravam um neologismo desnecessário, sugerindo "mundial" como alternativa.

Mas o dicionário Webster, o Oxford English e o Larousse francês aceitaram-na já no início dos anos 70. O Oxford cita sua utilização mais famosa, feita por Marshall McLuhan num conceito que se tornou emblemático, o de "aldeia global". A perspicácia de Mc-Luhan foi captar uma propriedade da cultura moderna, ou seja, a possibilidade de comunicação global, e afirmar que a recepção instantânea de imagens e vozes distantes mudava o conteúdo da cultura (Dicionário do pensamento social do século XX, 1996:340).

O termo globalização não tem uma definição única e universalmente aceita. De acordo com Held e McGrew (2001:11), ela tem sido diversamente concebida

como ação à distância (quando os atos de agentes sociais de um lugar podem ter conseqüências significativas para "terceiros distantes"); como compressão espaçotemporal (numa referência ao modo como a comunicação eletrônica instantânea vem desgastando as limitações da distância e do tempo na organização e na interação sociais); como interdependência acelerada (entendida como a intensificação do entrelaçamento entre economias e sociedades nacionais, de tal modo que os acontecimentos de um país têm um impacto direto em outros); como um mundo em processo de encolhimento (erosão das fronteiras e das barreiras geográficas à atividade socioeconômica).

Ainda segundo esses autores, o que distingue essas definições é a ênfase que se dá "aos aspectos materiais, espaço-temporais e cognitivos da globalização" (Held e McGrew, 2001:12). Os aspectos materiais estão relacionados aos fluxos de comércio, capital e pessoas em todo o globo. Os diferentes tipos de infra-estrutura como a física (transportes, sistemas bancários), a normativa (regras do comércio) e a simbólica (o inglês é considerado a língua acadêmica mundial) têm facilitado esses fluxos. Os aspectos espaço-temporais são, sem sombra de dúvida, os que mais têm possibilitado o enredamento de Estados e sociedades em sistemas mundiais.

Desse modo, as limitações do tempo social e do espaço geográfico já não impõem barreiras a muitas formas de interação ou organização social. Tudo isso foi amplamente favorecido pela multiplicação, em um curto intervalo de tempo, de redes de computadores interligados por satélites, cabos, e fibras ópticas, viabilizando mecanismos eletrônicos de transferência de dados/informações em alta velocidade. A rapidez dos fluxos nessa rede mundial tornou o papel-moeda, por exemplo, praticamente obsoleto, estimulando correntes 
contínuas de transações eletrônicas que passaram a atuar 24 horas por dia, acompanhando o ciclo dos fusos horários e operando em todos os mercados do mundo. É o non-stop das bolsas de valores (Sevcenko, 2001).

Nesse sentido, as distâncias parecem encolher e a velocidade relativa da interação social parece aumentar. Assim, vários acontecimentos em regiões distantes do mundo passam a ter um impacto imediato, implicando, inúmeras vezes, um tempo menor de reação para os que tomam decisões. Os aspectos cognitivos dizem respeito a isso, ou seja, se expressam em uma consciência crescente do modo como os acontecimentos distantes podem afetar os rumos locais. Nas palavras de Giddens (1991:69),

a estrutura conceitual do distanciamento tempo-espaço dirige nossa atenção à complexas relações entre envolvimentos locais (circunstâncias de co-presença) e interação a distância (as conexões de presença e ausência). Na era moderna, o nível de distanciamento tempo-espaço é muito maior (...) e as relações entre formas sociais e eventos locais e distantes se tornam correspondentemente "alongadas". A globalização se refere essencialmente a este processo de alongamento, na medida em que as modalidades de conexão entre diferentes regiões ou contextos sociais se enredam através da superfície da Terra como um todo (grifos no original, tradução alterada).

Held e McGrew (2001:13) enfatizam que a globalização "refere-se a uma mudança ou transformação na escala da organização social que liga comunidades distantes e amplia o alcance das relações de poder nas grandes regiões e continentes do mundo". No entanto, fazem um alerta:

não deve ser entendida como algo que prenuncia o surgimento de uma sociedade mundial harmoniosa, ou de um processo universal de interação global em que haja uma convergência crescente de culturas e civilizações. (...) A consciência da interligação crescente não apenas gera novas animosidades e conflitos, como pode também alimentar políticas reacionárias e uma xenofobia arraigada, uma vez que um segmento significativo da população mundial fica basicamente excluído de seus benefícios.

Nessa perspectiva, a globalização é um processo que também possui dimensão bastante desagregadora e, por isso mesmo, é muito contestada, já que, ao mesmo tempo em que as relações sociais se alongam lateralmente, as pressões para autonomia local e identidade cultural regional se fortalecem. Portanto, está longe de ser inteiramente benéfica em suas conseqüências. Para aqueles seres humanos que vivem muito distante da Europa e da América do Norte, esse processo, de acordo com Giddens (2000a:25), "tem uma desagradável aparência de uma ocidentalização - ou, talvez, de uma americanização" (Coca-Cola, McDonald's, CNN são exemplos de expressões culturais americanas que aparecem em todo o mundo). Além disso, a desigualdade gerada é tal que afasta o processo de globalização integralmente de um caráter universal, ou seja, uniformemente experimentado em todo o planeta. 
Como já foi assinalado, não existe uma definição universalmente aceita para o termo globalização. As posições adotadas por diferentes pensadores, em inúmeros debates que ocorreram ao longo dos últimos anos sobre essa temática, são contrastantes. Há os que questionam tudo o que se refere a ela - os céticos, e os que sustentam que ela é real e que suas conseqüências podem ser sentidas em toda parte - os globalistas ou radicais (Giddens, 2000a; Held e McGrew, 2001).

Segundo os céticos, o conceito de globalização é insatisfatório, uma vez que o termo "global" não pode ser interpretado como um fenômeno universal. Também não basta colocar o "global" no ápice de uma hierarquia de escalas de organização e interação sociais que vai do local para o nacional, o regional e o global. A não especificação dos referenciais espaciais do "global", na argumentação desse grupo, torna o conceito globalização tão amplo que comprometem sua operacionalização em termos empíricos e seu uso como veículo de compreensão do mundo contemporâneo. Os integrantes desse grupo entendem que termos como "internacionalização" e "regionalização" seriam conceituações mais válidas. Em suma, acreditam que a interdependência internacional é uma situação temporária, que o Estado nacional continua capaz de controlar a vida econômica e que o Estado de bem-estar social permanece intacto. (Held e McGrew, 2001:15).

A visão globalista ou radical sustenta que a globalização é real e que o mercado global está muito desenvolvido e é indiferente a fronteiras nacionais. Para os globalistas, a globalização implica uma reordenação das relações entre território e o espaço socioeconômico e político, porque à medida que as atividades econômicas, sociais e políticas transcendem as regiões e as fronteiras nacionais, estão desafiando o princípio territorial da organização social e política moderna (desgaste da soberania, da autonomia e da legitimidade do Estado e, portanto, declínio do Estado-nação). Rejeitam a afirmação de que o conceito pode ser puramente ideológico, ou como sinônimo do "imperialismo ocidental". Também não concebem a globalização como um fenômeno exclusivamente econômico e tecnológico. Conferem a esse fenômeno um status equiparável a outras dimensões da atividade social, reconhecendo "a complexidade intrínseca das forças que moldam as sociedades modernas e a ordem mundial" (Held e McGrew, 2001:18).

Nesse contexto mundial de transformações rápidas que afetam quase todos os aspectos da vida cotidiana, o desenvolvimento científico e tecnológico, a modernização da sociedade e a redefinição do tempo e do espaço social operada pela globalização impõem novas exigências educacionais, com repercussões tanto na interface da educação com o mundo do trabalho, quanto da educação com o exercício da cidadania. Essas novas exigências educacionais consistem em fenômeno de abrangência internacional, cuja tentativa de solução não tem prescindido do fortalecimento de instâncias não formais de educação (Fensham, 1999), da valorização da aprendizagem ao longo da vida, em especial na área de ciências (Young e Glanfield, 1998), e das conexões entre educação formal e não formal (Falcão, 1999).

Durante a década de 1980, um número considerável de países e a Organização das Nações Unidas para a Educação, Ciências e Cultura (UNESCO) assumiram um compromisso internacional no que diz respeito à educação em ciências: uma nova meta sob o slogan "ciência para todos". "A educação científica de todos os estudantes, enquanto futuros cidadãos, foi 
colocada em pé de igualdade com o objetivo original e tradicional da educação formal em ciências, relacionado com a seleção e a preparação de futuros cientistas" (Fensham, 1999:755).

A grande questão que os profissionais que elaboram os currículos de ciência ensinados nas escolas têm se colocado é como levar a cabo essa tarefa, que não é nada trivial, e para a qual diferentes abordagens têm sido exploradas.

Fensham (1999) chama a atenção para dois fatos importantes: que o poder e a influência exercidos por aqueles que defendem os processos dogmáticos/tradicionais para 0 ensino de ciências na elaboração e implementação dos currículos de ciência é tal que os currículos alternativos são usualmente reduzidos a simples remanejamentos de tópicos existentes; e que o conhecimento que o público adulto tem sobre os temas científicos mais atuais e relevantes não advém das experiências escolares e sim da ação da divulgação científica (dos grandes divulgadores/popularizadores da ciência), da midia eletrônica de qualidade e da atuação dos museus de ciência que trazem para as suas exposições, tanto os conhecimentos científicos/tecnológicos clássicos, quanto as temáticas atuais e/ou polêmicas.

Com base nesses pressupostos, os especialistas na área de educação em ciências têm buscado, notadamente na Europa, Estados Unidos, Austrália, mas também no Brasil, implementar programas de educação formal e não formal em ciências que possam contribuir para a formação de cidadãos críticos, capazes de apreciar a ciência como parte da cultura, de procurar o próprio enriquecimento cultural científico permanentemente, de questionar 0 conhecimento difundido pela mídia e de interagir de forma consciente com o mundo ao seu redor (Shamos, 1995).

No âmbito da Organização para a Cooperação e o Desenvolvimento Econômico (OCDE) e de seu Programme for International Student Assessment (PISA) há intensa tematização sobre o entendimento do termo "alfabetismo", cuja compreensão, hoje, é muito mais ampla do que a noção original: saber ler e escrever. Nas sociedades letradas/cultas, saber reproduzir os sistemas ortográfico e numérico é insuficiente para vivenciar plenamente a cultura escrita e responder às demandas atuais, uma vez que é necessário ir além de identificar códigos. Um cidadão contemporâneo tem de exercer as práticas sociais de leitura e escrita que circulam na sociedade em que vive. Nesse sentido, a aquisição de conhecimento e habilidade para 0 exercício pleno dessas práticas é um processo construído ao longo da vida e que acontece não somente na escola (educação formal), mas também por meio da interação com pares, colegas, amplas comunidades e com os diversos espaços de caráter cultural disponíveis no contexto social (educação não formal).

A característica chave desse entendimento ampliado de "alfabetismo" é o foco mais explícito no conhecimento, entendimento e habilidade requeridos para uma atuação efetiva na vida cotidiana em função da importância do papel da ciência, da matemática e da tecnologia na vida moderna e que requer, portanto, uma população adulta que não seja só capaz de ler e escrever, mas que seja também matemática, científica e tecnologicamente alfabetizada, visto que isso torna os indivíduos menos dependentes uns dos outros, fazendo com que os processos democráticos, os valores sociais e as oportunidades individuais não permaneçam dominados pelas elites cultas (OCDE, 2000).

Em virtude de esse debate não estar finalizado, os especialistas internacionais dos países-membros da OCDE/PISA propuseram a seguinte definição para a expressão alfabetismo 
científico, aqui entendida como o modo de ser de alguém que foi alfabetizado científica e tecnologicamente: "ser capaz de combinar o conhecimento científico com a habilidade de tirar conclusões baseadas em evidências de modo a compreender e ajudar a tomar decisões sobre o mundo natural e as mudanças nele provocadas pela atividade humana" (OCDE, 2000:76).

Em torno dessa definição, especialistas em educação em ciências contratados pela Organização para a Cooperação e o Desenvolvimento Econômico estabeleceram um quadro de referência conceitual sobre o que deveria ser privilegiado como as competências, os conhecimentos e as habilidades em ciências dos jovens de 15 anos de idade (OCDE, 1999). Esse quadro de referência conceitual serve de base para a construção das provas do PISA, que foram aplicadas em 32 países, inclusive o Brasil, em 2000. No final de 2001, serão divulgadas as primeiras análises. Sem assumir o quadro de referência conceitual desse Programa como algo que deva ter caráter normativo ou prescritivo para a educação brasileira, será interessante conhecer algumas características desse quadro conceitual.

O PISA define os três domínios - leitura, alfabetismo matemático, alfabetismo científico sobre os quais se apoia sua avaliação internacional administrada para estudantes de 15 anos não em termos do conteúdo do currículo escolar, mas em termos de conhecimentos e habilidades relevantes e necessárias para a vida adulta futura, caracterizada por rápidas mudanças e por uma profunda interdependência global. Fenshan (1999:761), em concordância, destaca que a escolha dos conceitos/conteúdos de ciência associada à essas habilidades deveria ser governada por critérios como: "relevância para situações cotidianas; relevância continuada durante toda a próxima década e além; e relevância para situações nas quais as atividades científicas são demonstradas". Nessa perspectiva e para transformar a definição do domínio alfabetismo científico em uma avaliação, o PISA identifica e privilegia três amplas dimensões. São elas: "processos científicos ou habilidades" - os processos mentais envolvidos na abordagem de questões (identificar evidências ou explicar conclusões); "conceitos e conteúdos" - o conhecimento científico e o entendimento conceitual requeridos para esses processos; e "contexto" - as situações nas quais os processos e o entendimento são aplicados (OCDE, 2000:76).

Segundo esse Programa e considerando essas dimensões, a avaliação de tais habilidades nos ajudaria a compreender como a educação formal e a não formal em ciências está preparando os futuros cidadãos para participarem em sociedades cada vez mais afetadas pela ciência e pela tecnologia. Os estudantes deveriam ser capazes de entender sobre a natureza da ciência, seus procedimentos, seus alcances, suas limitações, e de reconhecer que evidências são requeridas em uma investigação científica e que conclusões confiáveis poderiam ser tiradas dessas evidências. Cabe ressaltar que a preocupação do PISA

não é descobrir se os estudantes podem empreender investigações científicas por eles mesmos, mas se suas experiências escolares culminaram no entendimento dos processos científicos e na habilidade para aplicar os conceitos científicos que os tornariam capazes de tomar decisões sobre o mundo natural e as mudanças nele ocorridas em virtude da atividade humana (OCDE, 2000:77).

Espera-se que nos vários países cujos Sistemas de Ensino controlam a aprendizagem dos estudantes para responderem a essas demandas contemporâneas, as análises 
comparativas internacionais advindas da avaliação feita pelo PISA possam ampliar e enriquecer o quadro nacional, ao trazer subsídios para que as escolas direcionem seus esforços para uma aprendizagem significativa dos alunos e, em especial, para que autoridades possam considerar o modo pelo qual as condições de ensino e aprendizagem repercutem nos resultados escolares dos alunos.

Em dezembro de 2001 foram divulgados os primeiros resultados do PISA (OECD, 2001; INEP, 2001). Muito embora os resultados iniciais do PISA tenham focalizado com especial atenção a área de Leitura, os mencionados relatórios trazem também resultados relativos às áreas de Matemática e de Ciências, que serão as áreas focalizadas mais detalhadamente em 2003 e 2006, respectivamente. Com respeito ao Brasil, os resultados iniciais do PISA mostram desempenho extremamente precário, tanto em leitura quanto em matemática e ciências (OECD, 2001:53/79/88). Muito embora parte dos resultados brasileiros sejam conseqüência do atraso escolar que afeta parcela expressiva da população brasileira, as análises indicaram o fraco desempenho de alunos brasileiros cuja situação social e econômica é comparável à de alunos oriundos de países ricos da OCDE (INEP, 2001:67-68).

\section{Considerações Finais}

No cenário internacional, a relevância da educação pública para todos está presente desde a Revolução Francesa. No século XIX, a centralidade da idéia de progresso e o otimismo em relação à ciência e a tecnologia impulsionaram a educação em ciências, inclusive em espaços não formais, como exemplificam as Grandes Exposições Internacionais. No entanto, a ênfase da educação em ciências para todos esteve centrada na divulgação do otimismo em relação à ciência e em proposta de ensino que visavam mais a introjeção da confiança em sistemas especialistas do que no domínio efetivo da ciência e seus processos.

Nas últimas décadas o mundo vem experimentando diversas transformações. O sentido dessas modificações, relacionadas com a modernidade radicalizada e com a globalização, ainda é incerto. Ao longo deste trabalho, exemplificamos como muitas possibilidades são abertas mas também como novos riscos e problemas se colocam. No que se refere à educação em ciências, o cenário contemporâneo comporta múltiplas possibilidades de desenvolvimento. O ponto de partida dessas possibilidades está centrado na noção de que a sociedade não mais pode avançar a partir da confiança incondicional nos sistemas especialistas, o que redunda na superação da "eficácia" dos processos dogmáticos de ensino de ciências que limitam-se a ensinar a confiança em sistemas especialistas. Em domínios crescentes da vida social, cidadãos serão chamados a intervir em decisões sobre as quais os especialistas não têm a resposta certa. Nesse contexto, passa a ser crescentemente mais relevante cidadãos preparados para, na incerteza, decidir de modo fundamentado.

Para tal, a ciência que é ensinada na escola necessita responder às inúmeras mudanças que ocorrem no contexto social e ajudar a preparar os jovens para participarem como cidadãos, conformando o mundo no qual viverão. Fensham (1999) chamou a atenção para o desafio que enfrentam os profissionais que elaboram os currículos, principalmente os de ciência, para criar as bases necessárias à participação em uma sociedade impregnada pelos avanços da ciência. 
De acordo com Jenkins (1999), esses especialistas deveriam estruturar os currículos de modo a possibilitar o engajamento reflexivo de jovens estudantes em assuntos científicos que sejam de seu interesse e preocupação. De alguma forma, poderiam dar menos atenção e tempo aos conteúdos já bem estabelecidos de disciplinas como biologia, química e física, para poder abrir caminho à consideração de assuntos sobre os quais a ciência está menos segura ou ainda não tem uma resposta mais satisfatória, promovendo, então, "o entendimento dos estudantes sobre 'risco' e como ele pode ser avaliado" (Jenkins 1999:707). Isso iluminaria os professores de ciência a desenvolver estratégias que são mais familiares às áreas de história e leitura, nas quais o debate e as controvérsias constituem um território mais conhecido, sintonizando de modo mais amplo as práticas pedagógicas do professor de ciências com práticas já presentes, embora pouco prevalentes, no ensino de ciências.

Uma outra dimensão que pode favorecer a ampliação e o aperfeiçoamento do alfabetismo científico, no entendimento apresentado neste trabalho, é o estreitamento das conexões entre a educação formal e a não formal em ciências. Em outras palavras, 0 fortalecimento da relação museu-escola. A sociedade moderna entende que a educação é um processo que não acontece somente no espaço da escola, além de não se limitar ao período de formação escolar. Tal constatação não reduz o papel fundamental da escola, mas amplia a responsabilidade do Estado em fornecer meios de aprofundamento do conhecimento, pois não se pode entender o desenvolvimento sem que o cidadão tenha várias possibilidades e/ou oportunidades de atualizar sua bagagem de cultura.

Com o acelerado avanço de novas tecnologias e da ciência propriamente dita, o espaço não formal de educação vem ganhando destaque na elaboração das políticas nacionais de ensino e de divulgação. Tem também se constituído em um centro de referência devido às suas ações de cunho educacional e às pesquisas desenvolvidas na área de educação não formal em ciências, uma vez que tem refletido sobre a fundamentação da educação científica da sociedade como um todo e aprofundado o estudo do alfabetismo científico do cidadão.

É crescente a compreensão de que a educação em geral e a educação em ciências em particular deva ser promovida ao longo da vida das pessoas. Nesse contexto, os museus de ciência, por exemplo, têm um triplo desafio: funcionar como instituições de educação não formal, promovendo oportunidades de aprendizagem ao longo da vida; funcionar como instância de sensibilização para os temas científicos; contribuir para o desenvolvimento profissional de professores pois esses, mais do que todos, não podem prescindir de educação continuada em ciências.

No que diz respeito a esse último desafio - formação continuada de professores de ciências -, alguns museus de ciência localizados na cidade do Rio de Janeiro já tomaram iniciativas. Exemplo foi o projeto Formação Continuada de Professores: estratégias inovadoras em espaços formais e não formais de educação (1997-1999), elaborado pelo Museu de Astronomia e Ciências Afins (MAST) e a Faculdade de Educação da Universidade Federal Fluminense (UFF), com apoio financeiro da Finep, desenvolvido junto às escolas da rede municipal do Rio de Janeiro. No contexto desse projeto, foram produzidos materiais didáticos (modelos pedagógicos, cadernos instrucionais) que foram centralizados nas dez escolas-polo de ciências e matemática (os professores participantes agendavam o empréstimo para a utilização em sala de aula); cursos, priorizando o uso do museu como recurso didático; e 
pesquisas que avaliaram a utilização pelo professor do material didático produzido, bem como a verificação das inovações introduzidas na prática escolar como conseqüência da relação museu-escola.

Outro ponto que pode ser considerado no bojo da formação continuada, é a formação dos profissionais que atuam em diferentes dimensões das práticas educativas realizadas nos espaços não formais de educação (Nascimento e Ventura, 2001). Pesquisas em museus de ciência sobre os saberes da mediação (Queiroz, 2001) - entendidos como os diferentes conhecimentos e práticas sociais presentes no ato de mediar a relação entre a ciência e o público, nos seus aspectos científico, cultural e social - estão começando a ser desenvolvidas, evidenciando a necessidade de investir na formação específica do quadro profissional daqueles que atuam nas atividades educativas desses locais.

Essas iniciativas destacadas acima demostram o reconhecimento do papel da educação não formal promovida nos museus de ciência, no sentido de que esses espaços venham a desenvolver parcerias educacionais para a formação de profissionais para a educação formal e a não formal em ciências que atuem articulando essas duas formas de educar.

O conjunto desses aspectos destacados se configura como elemento essencial para que o país tenha condições de encaminhar a resolução de seus problemas sociais e econômicos em um mundo cada vez mais conectado, independentemente da avaliação que se faça dos prós e contras da globalização.

\section{Referências}

ANDERSON, P. (1996). Balanço do neoliberalismo. In: SADER, E.; GENTILI, P. (orgs.) Pósneoliberalismo: as políticas sociais e o estado democrático. Rio de Janeiro: Paz e Terra. pp. 9-37.

BECK, U. (1997). A reinvenção da política: rumo a uma teoria da modernização reflexiva. In: BECK, U.; GIDDENS, A.; LASH. S. Modernização reflexiva: política, tradição e estética no ordem social moderna. São Paulo: Editora da UNESP. pp. 11-71.

DICIONÁRIO DO PENSAMENTO SOCIAL DO SÉCULO XX. (1996). Rio de Janeiro: Jorge Zahar Ed.

FALCÃO, D. (1999). Padrões de interação e aprendizagem em museus de ciência. Dissertação (mestrado) - Programa em Educação, Gestão e Difusão em Biociências. Departamento de Bioquímica Médica do Instituto de Ciências Biomédicas, Universidade Federal do Estado do Rio de Janeiro (UFRJ), Rio de Janeiro.

FENSHAM, P. (1999). School science and public understanding of science. International Journal of Science Education, v.21(7):755-763.

FERREIRA, Aurélio Buarque de Holanda. (1999) Novo Aurélio Século XXI: o dicionário da língua portuguesa. 3.ed. Rio de Janeiro: Nova Fronteira.

FRIGOTTO, G. (1998). La produtividad de la escuela improductiva.1.ed. Buenos Aires: Miño. GIDDENS, A. (1991). As conseqüências da modernidade. São Paulo: Editora da UNESP.

GIDDENS, A. (1997). Risco, confiança, reflexividade. In: BECK, U.; GIDDENS, A.; LASH. S. Modernização reflexiva: política, tradição e estética no ordem social moderna. São Paulo: Editora da UNESP. pp. 219-234. 
GIDDENS, A. (2000a). Mundo em descontrole: o que a globalização está fazendo de nós. Rio de Janeiro: Record.

GIDDENS, A. (2000b). A terceira via: reflexões sobre o impasse político atual e o futuro da social-democracia. Rio de Janeiro: Record.

HELD, D.; McGREW, A. (2001) Prós e contras da globalização. Rio de Janeiro: Jorge Zahar Ed. INSTITUTO NACIONAL DE ESTUDOS E PESQUISAS EDUCACIONAIS. (2001). PISA 2000: relatório nacional. Brasília: INEP.

JENKINS, E. W. (1999). School science, citizenship and the public understanding of science. International Journal of Science Education, v.21(7):703-710.

KUHLMANN JÚNIOR, M. (2001). As grandes festas didáticas: a educação brasileira e as exposições internacionais (1862-1922). Bragança: Editora da Universidade São Francisco.

NASCIMENTO, S. S. do; VENTURA, P. C. S. (2001). Mutações na construção dos museus de ciências. Pro-Posições, v.12, n.1 (34) - março, pp.126-138.

NEVES, M. de S. (2001). Uma arena pacífica. In: MAST. Imagens do progresso: os instrumentos científicos e as grandes exposições. Rio de Janeiro: MAST. pp. 2-8.

ORGANISATION FOR ECONOMIC CO-OPERATION AND DEVELOPMENT. (1999). Measuring students knowledge and skills: a new framework for assessment. Paris: OECD.

ORGANISATION FOR ECONOMIC CO-OPERATION AND DEVELOPMENT. (2000). Measuring students knowledge and skills: the Pisa 2000 assessment of reading, mathematical and scientific literacy. Paris: OECD.

ORGANISATION FOR ECONOMIC CO-OPERATION AND DEVELOPMENT. (2001). Knowledge and skills for life: first results from PISA 2000. Paris: OECD.

PERNOUD, R. Histoire de la bourgeosie em France: des origines aux temps modernes apud NÓVOA, A. (1991). (org.). Profissão professor. Porto: Porto Editora. pp. 110-111.

PERRENOUD, P. (1996) Enseigner: agir dans l'urgence, décider dans l'incertitude. Savoirs et compétences dans un métier complexe. Paris: ESSE.

PLUM, W. Exposições mundiais no século XIX: espetáculos da transformação sociocultural apud KUHLMANN JÚNIOR, M. (2001). As grandes festas didáticas: a educação brasileira e as exposições internacionais (1862-1922). Bragança: Editora da Universidade São Francisco. pp. 26.

QUEIROZ, G. (2001). Os saberes da mediação na educação em museus de ciências e suas relações com o contexto escolar. Rio de Janeiro: MAST. 15 p. (Projeto de Pesquisa em andamento, com financiamento da FAPERJ).

SEVCENKO, N. (2001). A corrida para o século XXI: no loop da montanha-russa. São Paulo: Companhia das Letras (Virando séculos; 7).

SHAMOS, M. (1995). The myth of scientific literacy. New Brunswick, NJ: Rutgers University Press.

YOUNG, M.; GLANFIELD, K. (1998). Science in post-compulsory education: towards a framework for a curriculum of the future. Studies in Science Education, v. 32, pp. 1-20.

\section{Abstract}




\section{Scientific Literacy: new challenges in the context of globalisation}

The present study has the aim to give a general view of the historical and conceptual issues which deal with the concept of globalisation and its effects on the patterns of the relationship between science and society as appears in the works of the sociologists Anthony Guiddens, David Held, Anthony McGrew and Nicolau Sevcenko. Based on these reflections on modernity, globalisation and the relationship between science and society, we examined the cultural and scientific literacy level which are required for insertion in contemporary society. The analyses

proved that in growing fields of social life, citizens are summoned to intervene in decisions about issues in which experts do not have the "right answer".

Key-words: scientific literacy; science and globalisation; risk and science education

\section{Correspondência}

Profa. Sibele Cazelli, Coordenação de Educação, Museu de Astronomia e Ciências Afins, Rua General Bruce, 586, São Cristóvão, Rio de Janeiro, RJ - Cep. 20921-040. Correio eletrônico: sibele.trp@terra.com.br

Prof. Creso Franco, Departamento de Educação, Pontifícia Universidade Católica do Rio de Janeiro, Rua Marquês de São Vicente, 225, Gávea, Rio de Janeiro, RJ - Cep. 22453-900. Correio eletrônico: creso@edu.puc-rio.br

\section{Identificação}

Sibele Cazelli e Creso Franco

Alfabetismo Científico: Novos Desafios no Contexto da Globalização 